\title{
Intelligent Prediction Model for Run-of-River Flow Considering Electricity Extreme Conditions
}

\author{
Raju Rai and Ken Nagasaka
}

\begin{abstract}
The Artificial neural networks (ANNs) is becoming a common analysis of hydrology and water resources development, management, modeling and prediction systems. Nepal is a developing country with rich in water resources, the electricity demand is very high but generation is very low. The river flow rate plays an increasingly important role in electricity generation in Nepal. To reduce the power shortage in a local community, prediction of river flow is most necessary for the Run-of-River hydropower plants in Nepal. In this research, the river flow forecasting model based on the Artificial Neural Networks (ANNs) was developed using the Neural Connection. The performance of the developed model based on the results of this research, prediction of river flow was observed. One week of flow prediction test was conducted and one week ahead of its hydropower generation potential was identified. Employing Radial Basis Function Network (RBFN) method for forecasting of river flow and observed less than $8 \%$ of error of test data for one week. It has been analyzed that river flow rate prediction helps to reduce the demand for electric power and generation of hydropower plants. The prediction method optimizes and plan for the future system. The paper analyzes the river flow prediction and technical potential of electricity generation of the hydropower plant.
\end{abstract}

Index Terms-Artificial neural network, prediction, power shortage, run-of-river, hydropower plant, RBFN, Nepal.

\section{INTRODUCTION}

Nepal is a developing country with an enormous potential of Run-of-River hydropower plants having more than 6000 rivers. All the rivers running down from the high Himalayas and hills. All the rivers flow from north to south from the elevation high to low therefore the river flow rate is high. Nepal has a huge hydropower potential of $83 \mathrm{GW}$, out of which $42 \mathrm{GW}$ is economically feasible but only $1178.30 \mathrm{MW}$ was developed. The electricity demand of Nepal is more than $1200 \mathrm{MW}$, relatively high in comparison to supply [1]. More than $90 \%$ of electricity is supplied through hydropower plants. Most of the hydropower plants are Run-of-River and the electricity generation depends upon the river flow rate. More than $70 \%$ of Nepal's population is suffering from load shedding. Most of the remote communities, villages are isolated from the energy supplies and basic energy requirements are fulfilled by kerosene lamps and firewood flames in the remote areas. Nepal heavily dependent on fossil fuel and coal to fulfill the energy across the country. The

Manuscript received March 10, 2018; revised July 5, 2018

Raju Rai is with the Department of Electronic and Information Engineering, Tokyo University of Agriculture and Technology, Tokyo, Japan (e-mail: raj_shang@hotmail.com).

Prof. Ken Nagasaka is with the Department of Electrical and Electronic Engineering, Tokyo University of Agriculture and Technology, Tokyo, Japan (e-mail: bahman@cc.tuat.ac.jp). electricity demand has been increasing in Nepal by 7 to $9 \%$ per year [2]. In the winter season there is daily minimum 4 to 5 hours load shedding. Nepal was declared an energy crisis state in early 2008. To fulfill the peak demand across the country, the government buys huge amounts of electricity from our neighboring country India. During the massive earthquake of magnitude 7.8 in 25 April 2015 resulted in a loss of thousand lives and about $10.95 \%$ of households were affected across the country [3]. Reducing domestic power production by $35 \%$ according to Nepal Electricity Authority (NEA). Lots of hydropower projects has suffered serious damages result in daily power shortage in most of the places in Nepal. The main objective of this research is to predict the river flow rate and from that analysis we can generate more electricity in future and minimize the power shortage in Kathmandu, the capital city of Nepal during the disaster time or emergency situation. Although Nepal's water resources are very rich, having a high potential of electric power. In order to meet the increasing power demand, there is a best opportunity to predict the river flow rate to promote hydropower projects. Thus, this technique will have an important role in generating more electricity to reduce the power shortage and dependent upon its own resources in future. Based on the water flow rate and prediction we identified the river flow rate of Trishuli river and potential of electricity generation. From the one year available daily river flow value and weather forecast data, it's to determine the river flow prediction for spring, summer, autumn and winter season and its electric power generation capacity for one week ahead for the spring season. In this manner, generation of energy on a certain day can be determined. With an available approximate demand, the period of over and under generation will be identified. Once a river flow rate is predicted, new hydropower plants installed, utilization of woods or gasoline for their cooking, heating, lighting, etc. would be minimized, which in effect reduces the emission of greenhouse gases. However, analysis also plays a vital role in design and operation of dams, water supply, flood mitigations and potential of electricity generation. Various types of modeling techniques had been used to predict the river flow rate. In this research, we used Radial Basis Function Network (RBFN) for analyzing river flow prediction results. Some studies reported that the successful application of ANN models in comparison with the conventional ones with better simulation results [4]. The prediction of river flow idea helps to forecast electricity generation to overcome power shortage.

\section{THE StUdy AREA}

The origin of Trishuli river is high Himalayas and flows 
from north to south direction. This river is an important water source for economic activities in the region. In this research, the study area consists of a mountains region, high hills and the river flow rate observed at Betrawati station, the drain area is about $4110 \mathrm{~km}^{2}$ located at the central part of Nepal [5]. The approximate location of this study is shown in Fig. 1. The study area located near Kathmandu, the capital city of Nepal. The demand for electricity of Kathmandu, Nepal is approximately 350-400 MW [6] and demand is increasing every year but generation is not sufficient. We will require at least more than $1500 \mathrm{MW}$ of electricity for Kathmandu alone within the next decade. Downstream river flow data were collected from the Betrawati station [5] and weather forecast data from the world weather online [7] and analyzed using the RBFN model.

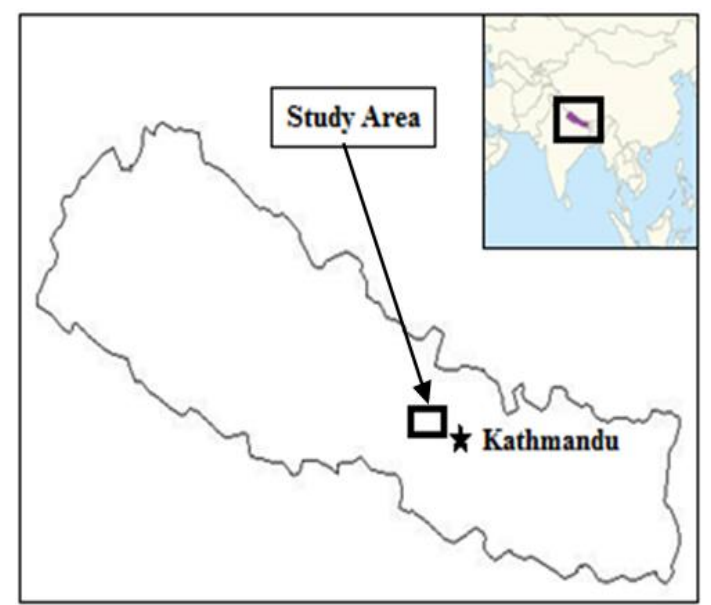

Fig. 1. Location of the study area in Nepal [Google Map].

In Nepal, based on the Nepal climatic zone as classified by the Nepal meteorological department there are four seasons, between March to May Spring season, between June to August Summer season, between September to November Autumn season and between December to February winter season [5]. In summer season (between June-August) the river flow rate has been increase because of rainfall and snow melt in the Himalayan region, whereas the winter season (between December-February) has been found to be decreasing. The minimum and maximum river flow rates are observed in March $36.10 \mathrm{~m}^{3} / \mathrm{s}$ and in July $841 \mathrm{~m}^{3} / \mathrm{s}$ respectively. The maximum and minimum flow for the four seasons are the most important periods for snow melt. However, snowmelt and steady river flow also effects the hydropower generation. The seasonal difference in river flow rate creates difficulties to balancing the electric power. However, in the context of Nepal, production of hydropower drop to one third of installed capacity [2]. In the Trishuli watershed, more additional cascade dams will require for hydropower development in near future. In Nepal hydropower has high potential but there are not enough power plants to fulfill the demand, most of the villages and remote communities are isolated from the energy supplies and their basic energy requirements are fulfilled by firewood flames and kerosene lamps.

\section{MODEL USED IN THE STUDY}

In artificial intelligence methods, the artificial neural network is widely used in forecasting because of its ability to learn nonlinear relationships. The Artificial Neural Network RBFN model is a computational approach and is capable of modeling linear and nonlinear systems. Many kinds of ANN models have emerged in last decades for solving the various problem. For example, river flow prediction using artificial neural networks [8] [9], neural network based water inflow forecasting [10]. This model usually has three layers known as input layer, hidden layer and output layer. On this simulation study, the input layer consists of 4 units: temperature $X_{1}(k)$, rainfall $X_{2}(k)$, cloud $X_{3}(k)$ and humidity $X_{4}(k)$. The output layer contains one unit $\hat{y}(k)$ represents the river flow value. Finally, the selected architecture of RBFN models was $(4,8,1)$ with Gaussian function of centers 8 . In Neural Connection the user must choose a number of centers and this number will equivalent to the number of hidden neurons [11]. The hidden neuron $i$ with pattern $s$ has the form:

$$
\phi_{s}(i)=\exp \left(-\frac{\left\|s-c_{i}\right\|}{2 \sigma_{i}^{2}}\right)
$$

Each hidden unit has $\sigma$ width value which defines the nature and scope of respective field units. The output layer is parameterized by the weights, $w$ between the hidden and output layers. The predicted output is calculated by the equation 2 .

$$
O_{k}(s)=\sum_{j=1} w_{j k} \times \emptyset_{s}(j)
$$

where, for the output $k$ of record $s$ as $O_{k}(s), j$ describes the hidden neuron, i.e. the $j^{t h}$ center of architecture model. The weights are denoted by $w_{j k}$ and are initialized to small random values (between -0.001 and 0.001). Application of the neural network method in flood forecasting and prediction capabilities [12]. The noise level in the hydrological dataset is usually ranging between $5 \%$ and $15 \%$ and the total runoff is calculated as direct runoff and base flow. The model structure of the neural network used in this study shown in Fig. 2, which represents the model structure. Development of the neural network model to predict the flow for Trishuli river, Nepal. The model can be used in predicting one week flow forecasting of four seasons by the providing the past successive yearly flow of the same week. In our study, we consider the one week river flow data of the spring season. Assuming that if some kind of emergency situation happened in this period (for example, the earthquake of magnitude 7.8 in 25 April 2015) the potential of power generation was identified at that period. This research will help to lead the efficient operation, planning and development of hydropower plants also helpful for water resources management system and early warning system in flood forecasting system. The main aim of this paper was to forecast the weekly river flow rate to identify the potential of hydropower. In this research, the ANN model based on RBFN algorithm is used in three modes i.e. training, validation and testing. RBFN has an internal representation of hidden processing. The training data is used to adjust the weight of the network interconnection of the model. Once all the weight of the model has been identified the model is ready to train. To monitor the performance of the network validation is done apart of from taking training data as a validation data. This is done because in RBFN is overtraining which cause network performance not reliable. The train RBFN data is activated by 
the testing data of neural network.

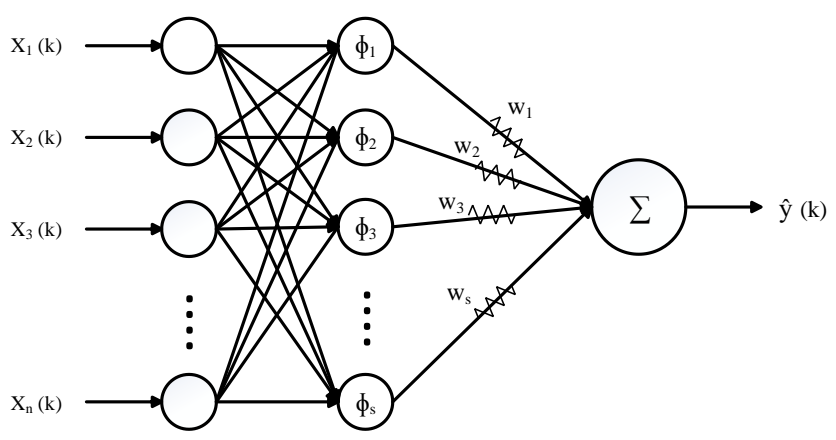

Fig. 2. The architecture of RBFN model in this study.

\section{STATistical PeRformanCE}

In this research, the input data, target data and test data sets are firstly normalized in the range of 0 to 1 [13]. The normalization is done by using the following equation.

$$
\bar{X}=\frac{\mathrm{X}-X_{\min }}{X_{\max }-X_{\min }}
$$

where, $\bar{X}$ is the standardized value of the input, $X_{\text {min }}$, minimum of actual value, $X_{\max }$, maximum of actual value and $X$, original value. The Mean Absolute Percentage Error (MAPE) is used to determine the relative error between the actual and predicted value. As the obtained result is close to zero the better will be the network performance. MAPE is calculated by the averaging the percentage difference between the actual and predicted value. Where $A i$ is the actual value, $P i$ is the predicted value and $N$ is the total number of data points.

$$
M A P E=\frac{\sum_{i=0}^{N} \frac{\left|A_{i}-P_{i}\right|}{A_{i}} * 100}{N}
$$

TABLE I: CORRELATION ANALYSIS OF INPUTS AND TARGET

\begin{tabular}{|c|c|c|c|c|c|}
\hline & Temp. & Rain & Cloud & Humidity & Flow \\
\hline Temp. & 1 & & & & \\
\hline Rainfall & 0.407 & 1 & & & \\
\hline Cloud & 0.324 & 0.746 & 1 & & \\
\hline Humidity & 0.183 & 0.567 & 0.623 & 1 & \\
\hline Flow & 0.516 & 0.703 & 0.658 & 0.626 & 1 \\
\hline
\end{tabular}

\section{CORRELATION OF INPUTS AND TARGET}

Correlation analysis is carried out to measure the strength of a relationship between the data sets. The coefficient of correlation varies between 0 and 1, 1 indicates the perfect correlation. In this paper, the inputs and target correlation were analyzed. Table I, shows the positive correlation in the collected datasets.

\section{SCENARIOS FOR ELECTRICITY EXTREME SitUATIONS}

Besides the normal operation of power system, we also need to consider some situations in case of any emergency or disasters which were happened several times in Nepal. The current energy demand is extremely high due to multiple reasons, for example, river flow level decreases significantly and electricity production is only about $30 \%$ to $35 \%$ of installed capacity. Also, in winter season majority of small and medium industries have been shut down and made the economy import oriented. To overcome this situation we have considered three scenarios.

Scenario 1: The prediction of river flow value for run-of-river hydropower plant for the spring season. The electricity will be mostly deficit in spring and winter season but also we had some emergency case such as disaster: the earthquake of magnitude 7.8 in 25 April 2015 and in flooding in August 2017. In this study, we considered if some emergency case were happened in spring season at that situation from this research the potential of electricity was identified. According to our actual and predicted river flow value we have calculated the actual and predicted value of power generation, demand and supply of spring season of 2013. The results are shown in Table II. The theoretical hydropower potential that can be generated from the run-of-river is defined by the equation 5 [14]. For this research the elevation head of water is considered as 45 meter approximately and efficiency of the hydropower plant is considered $90 \%$.

$$
P=\rho \cdot g \cdot H \cdot Q \cdot \eta
$$

where,

$P$ : Electrical power produced, (W)

$\rho$ : Density of water, $\left(\mathrm{kg} / \mathrm{m}^{3}\right)$

g: Acceleration due to gravity, $\left(\mathrm{m} / \mathrm{s}^{2}\right)$

$H$ : Elevation head of water, (m)

$Q$ : Flow rate of water, $\left(\mathrm{m}^{3} / \mathrm{s}\right)$

$\eta$ : Efficiency of the hydropower plant

TABLE II: PREDICTIONS FOR ELECTRICITY GENERATION POTENTIAL AND PEAK DEMAND IN THE SPRING SEASON

\begin{tabular}{|c|c|c|c|c|c|}
\hline $\begin{array}{c}\text { Prediction } \\
(\text { day ahead })\end{array}$ & $\begin{array}{c}\text { River } \\
\text { flow } \\
\left(\mathrm{m}^{3} / \mathrm{s}\right)\end{array}$ & $\begin{array}{c}\text { Design discharge } \\
\left(\mathrm{m}^{3} / \mathrm{s}\right) \\
(\text { Approx. }\end{array}$ & $\begin{array}{c}\text { Theoretical } \\
\text { potential } \\
{[\mathrm{MW}]}\end{array}$ & $\begin{array}{c}\text { Technical potential } \\
{[\mathrm{MW}]}\end{array}$ & $\begin{array}{c}\text { Peak Demand } \\
{[\mathrm{MW}] \text { (Approx.) }}\end{array}$ \\
\hline Day $(\mathrm{t})$ & 41.46 & 29.02 & 16.47 & 11.52 & $295-335$ \\
\hline Day $(\mathrm{t}+1)$ & 42.32 & 29.62 & 16.81 & 11.76 & $300-350$ \\
\hline Day ( $\mathrm{t}+2)$ & 41.09 & 28.76 & 16.32 & 12.63 & $295-330$ \\
\hline Day $(\mathrm{t}+3)$ & 45.45 & 31.81 & 16.67 & 11.66 & $305-330$ \\
\hline Day $(\mathrm{t}+4)$ & 41.97 & 29.37 & 14.64 & 10.25 & $300-325$ \\
\hline Day $(\mathrm{t}+5)$ & 36.86 & 25.80 & 15.52 & 10.86 & $310-340$ \\
\hline Day $(\mathrm{t}+6)$ & 39.07 & 27.34 & & & \\
\hline
\end{tabular}


TABLE III: ACTUAL AND PREDICTED PARAMETERS FOR ELECTRICITY GENERATION AND PEAK DEMAND IN THE SPRING SEASON

\begin{tabular}{|c|c|c|}
\hline Season & $\begin{array}{c}\text { Spring } \\
\text { (Actual) }\end{array}$ & $\begin{array}{c}\text { Spring } \\
\text { (Predicted) }\end{array}$ \\
\hline $\begin{array}{c}\text { Maximum river flow }\left(\mathrm{m}^{3} / \mathrm{s}\right) \\
\text { Date: } 5 / 27 / 2013\end{array}$ & 209 & 209.55 \\
\hline $\begin{array}{c}\text { Minimum river flow }\left(\mathrm{m}^{3} / \mathrm{s}\right) \\
\text { Date: } 3 / 2 / 2013\end{array}$ & 36.1 & 42.50 \\
\hline $\begin{array}{c}\text { Maximum theoretical potential } \\
{[\mathrm{MW}]}\end{array}$ & 83.03 & 83.25 \\
\hline $\begin{array}{c}\text { Minimum theoretical potential } \\
{[\mathrm{MW}]}\end{array}$ & 14.34 & 16.88 \\
\hline $\begin{array}{c}\text { Maximum technical potential } \\
{[\mathrm{MW}]}\end{array}$ & 58.06 & 58.17 \\
\hline $\begin{array}{c}\text { Minimum technical potential } \\
{[\mathrm{MW}]}\end{array}$ & 10.02 & 11.80 \\
\hline $\begin{array}{c}\text { Maximum Demand }[\mathrm{MW}] \\
\text { (Approximate) }\end{array}$ & $270-350$ & $275-360$ \\
\hline $\begin{array}{c}\text { Minimum Demand }[\mathrm{MW}] \\
\text { (Approximate) }\end{array}$ & $260-350$ & $270-355$ \\
\hline
\end{tabular}

The one week prediction of river flow value and its potential generation of electric power will not sufficient to solve the power crisis because the demand of Kathmandu is very high but it will help to supply of electric power for a couple of days to overcome the power outage across the Kathmandu valley. Similarly, Table III shows the actual and predicted of maximum and minimum river flow value and its electricity generation potential for spring season.

Scenario 2: Secondly, require small and medium types of hydropower plants. A medium scale hydro power plant is feasible when there is an abundant supply of water. Based on the available river water we proposed two medium head hydropower plant downstream of this river. Which was already published by the authors of this paper [15].

Scenario 3: Finally, the government of Nepal must repair, maintain and build the new transmission lines to reduce the power losses. And, minimize the power crisis by power wheeling with our neighbor country India and exchange power for summer-winter and vice-versa.

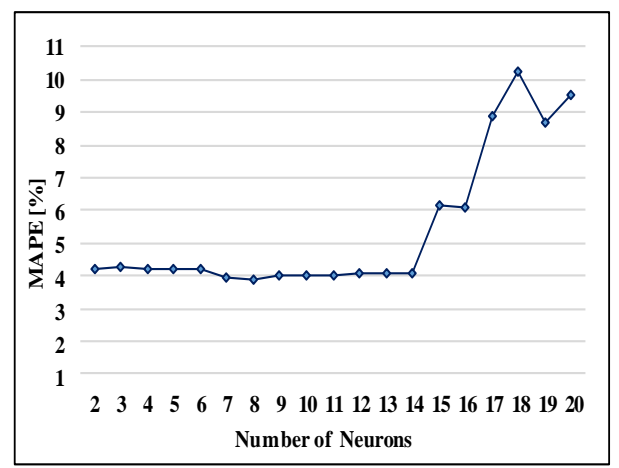

Fig. 3. The number of neurons in the hidden layer and MAPE.

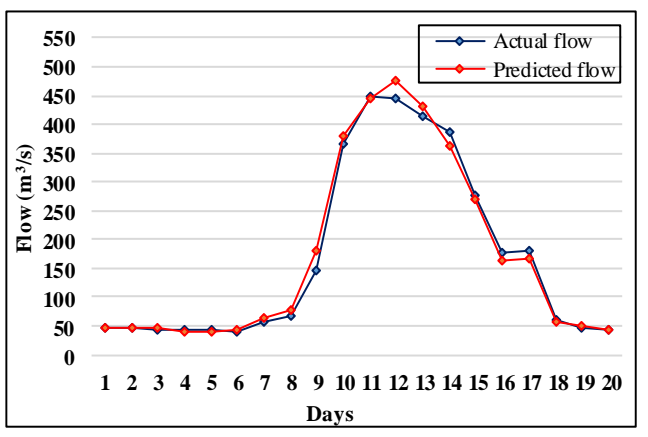

Fig. 4. Testing result for 20 randomly selected days of one year.

\section{RESULTS AND DISCUSSION}

The hydrological and downstream data used for this simulation study were obtained from the Government of Nepal, Department of Hydrology and Meteorology (DHM), Kathmandu, Nepal. The weather forecast data were collected from the World Weather Online. In the training phase, we used the daily average data of 2013 and divided all these data into four seasons. Every season was used to train the network and one week data was used for the testing phase. Four inputs and one output were set for the network model. The output is one i.e. one week river flow prediction. Finally, the architecture of RBFN model was constructed. All internal parameters of RBFN model were selected as required. The Fig. 3 shows the number neurons in the hidden layer and Mean Absolute Percentage Error (MAPE) of our spring model. Figs. 4 and 5 shows the test result for 20 and 15 randomly selected data from one year respectively.

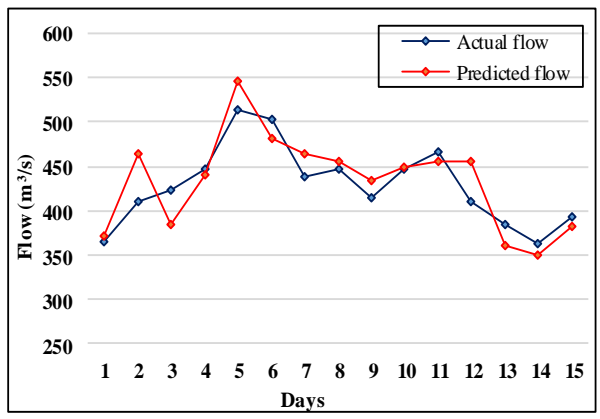

Fig. 5. Testing result for 15 high flow randomly selected days of one year.

Standard deviation (SoV) and Coefficient of variation $(\mathrm{CoV})$ were identified. Table IV shows the corresponding statistical parameters of the testing phase.

TABLE IV: StATISTICAL PARAMETERs OF THE TESTING PHASE

\begin{tabular}{|l|c|c|c|}
\hline Testing Results & $\begin{array}{c}\text { SoD } \\
\left(\mathrm{m}^{3} / \mathrm{s}\right)\end{array}$ & $\begin{array}{c}\text { CoV } \\
\left(\mathrm{m}^{3} / \mathrm{s}\right)\end{array}$ & $\begin{array}{c}\text { MAPE } \\
(\%)\end{array}$ \\
\hline 20 data set & 160.03 & 0.93 & 7.25 \\
\hline 15 data set & 53.14 & 0.12 & 5.02 \\
\hline
\end{tabular}

As we can see from the results RBFN was able to learn and predict the river flow rate. Figs. 6 and 7 shows the one week test result of spring and summer season. In the spring season it demonstrated that the network error is less than $4 \%$ for one week test result. However, in the summer season the network error is relatively high in comparison to spring and winter season and we have a high volume of river flow and the flow rate varies from minimum $134 \mathrm{~m}^{3} / \mathrm{s}$ to maximum $841 \mathrm{~m}^{3} / \mathrm{s}$.

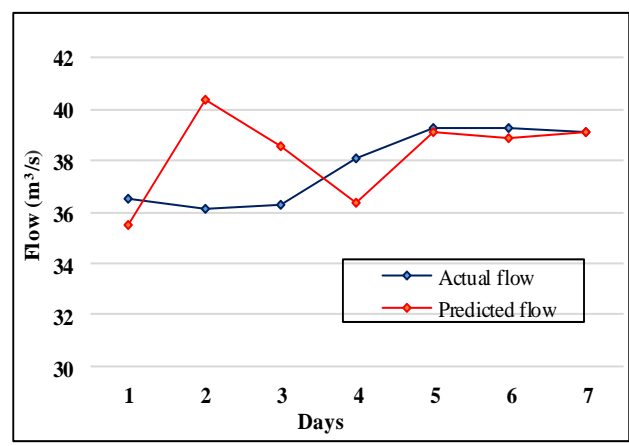

Fig. 6. The actual versus predicted flow value of test phase for the spring season. 


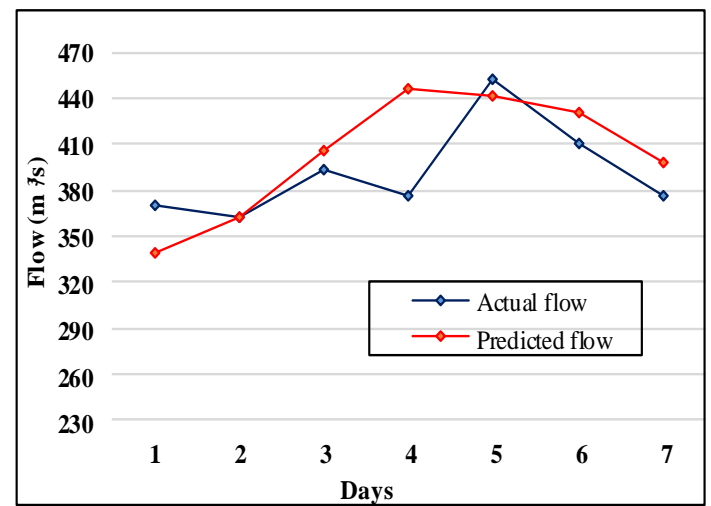

Fig. 7. The actual versus predicted flow value of test phase for the summer season.

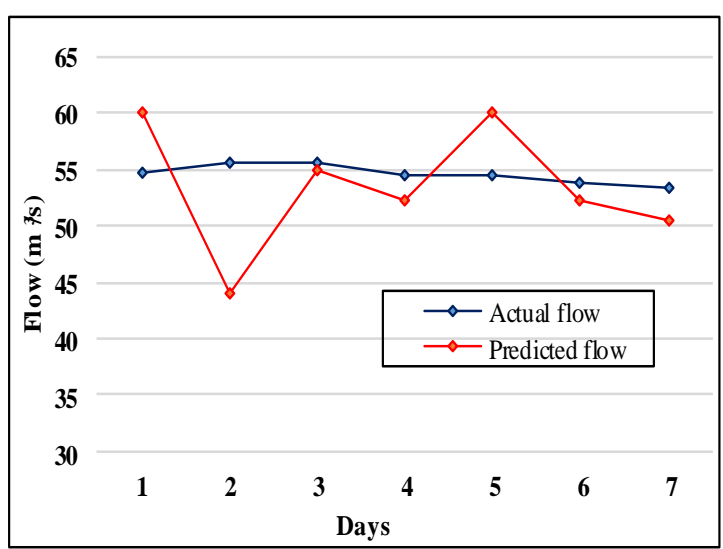

Fig. 8. The actual versus predicted flow value of test phase for the autumn season.

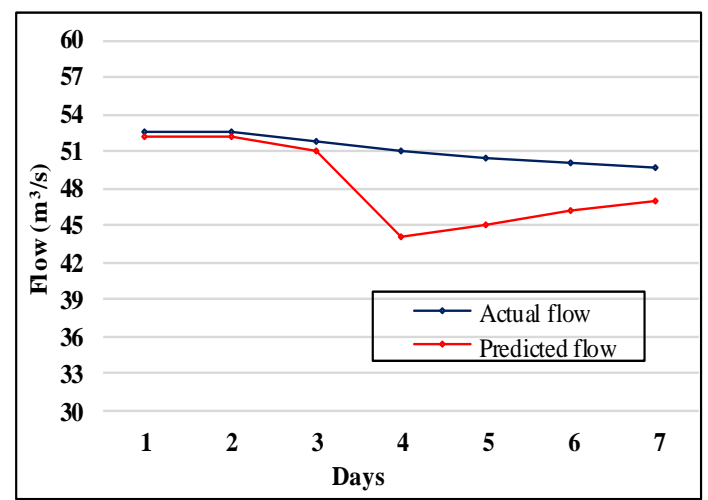

Fig. 9. The actual versus predicted flow value of test phase for the winter season.

In the autumn season, the river flow rate starts to decrease and becomes minimums $3.71 \%$ in the spring season. One week test result of autumn and winter season are shown in Figs. 8 and 9. The statistical parameters of actual and predicted of river flow at testing phase are shown in Table V. Furthermore, Table V shows MAPE increases as summer and autumn season. Increasing the test data error for more than one week will increase the MAPE. Therefore the predicted values of river flow will be significantly different. As shown in Table $\mathrm{V}$, the maximum error was $7.71 \%$ and the minimum was $3.71 \%$ for one week. In addition, to predict the river flow rate from RBFN method could be applied for its better performance. Table V illustrates the differences between the predicted river flow rates of Trishuli river at different seasons. The predicted average lowest and highest river flow rates are $37.80 \mathrm{~m}^{3} / \mathrm{s}$ and $403.39 \mathrm{~m}^{3} / \mathrm{s}$ in spring and summer season.
TABLE V: STATISTICAL PARAMETERS OF THE PREDICTED FlOW OF ONE

\begin{tabular}{|c|c|c|c|c|}
\hline \multicolumn{5}{|c|}{ WEEK FOR THE TESTING PHASE } \\
\hline Test result & Spring & Summer & Autumn & Winter \\
\hline $\begin{array}{c}\text { Average actual } \\
\text { flow } \\
\left(\mathrm{m}^{3} / \mathrm{s}\right)\end{array}$ & 37.80 & 391.71 & 54.60 & 51.20 \\
\hline $\begin{array}{c}\text { Average } \\
\text { predicted flow } \\
\left(\mathrm{m}^{3} / \mathrm{s}\right)\end{array}$ & 38.29 & 403.39 & 53.40 & 48.20 \\
\hline $\begin{array}{c}\text { Coefficient of } \\
\text { variation } \\
\text { (actual) }\end{array}$ & 0.03 & 0.08 & 0.01 & 0.02 \\
\hline $\begin{array}{c}\text { Coefficient of } \\
\text { variation } \\
\text { (predicted) }\end{array}$ & 0.04 & 0.10 & 0.10 & 0.07 \\
\hline \begin{tabular}{c} 
MAPE $(\%)$ \\
\hline
\end{tabular} & 3.71 & 6.30 & 7.71 & 5.71 \\
\hline
\end{tabular}

In the natural flow regime, the minimum monthly flow for the all four seasons is more than $30 \mathrm{~m}^{3} / \mathrm{s}$. However, the flow rates in all seasons are unregulated flow because of the function of ecology. The maximum and minimum flows are the most important periods for snow melt. The average predicted flow is high in comparison to average actual flow. The RBFN approach gives much better prediction than the traditional method.

Besides the one week test of all four season, we predicted one week ahead of river flow forecasting and potential of electricity generation. The testing result was obtained less than $6 \%$ error. The predicted river flow value with less than $6 \%$ error was used for to predict the hydropower potential. The Fig. 10 shows the result of testing phase for the spring season. Table VI shows the corresponding errors.

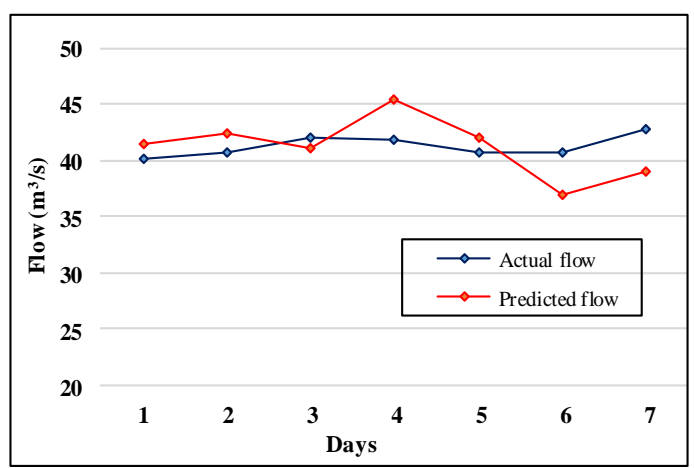

Fig. 10. The test result for one week ahead of the spring season.

TABLE VI: TRAINING AND TESTING PHASE FOR THE SPRING SEASON

\begin{tabular}{|c|c|}
\hline Spring season & MAPE [\%] \\
\hline Testing & 5.62 \\
\hline
\end{tabular}

\section{CONCLUSION}

In this research, based on radial basis function RBFN model was developed for simulating the hydrological behavior of river flow. The performance of the model in testing phase was quite similar to actual values. The model was constructed to predict seasonal river flow. The RBFN model provided improved weekly forecast during the testing phase. Based on the predicted river flow data, we calculated the potential of electricity and identified the potential of electricity for one week for the spring season. The obtained research results from the artificial neural network indicate 
that the RBFN network model is more capable to predict river flow. The performance of river flow model depends on the input parameters, selection of training and testing data and has a strong relationship with climate elements of that area. River flow prediction models are important tools in hydropower development and water resources management. This research was mainly focused on prediction of river flow at different seasons. However, we consider the minimum, maximum and one week river flow condition of the spring season to predict the river flow value and potential of electricity. In case of Nepal, to reduce the power shortage in a local community and urban areas this kind of research is most important and necessary. Improvement on the performance of river flow prediction models have never been applied like in Trishuli river, therefore, this research will more useful as hydropower development and water resources systems.

\section{ACKNOWLEDGMENT}

The authors would like to acknowledge the Department of Hydrology and Meteorology (DHM), Kathmandu, Nepal and Nepal Electricity Authority (NEA).

\section{REFERENCES}

[1] Nepal Electricity Authority. Kathmandu, Nepal, Annual report 2013-2014. [Online]. http://www.nea.org.np/anual-report.html

[2] Nepal Electricity Authority. Kathmandu, Nepal, Annual report 2014-2015. [Online]. Available: http://www.nea.org.np/anual-report.html

[3] Ministry of Home Affairs. Nepal, Nepal earthquake 2015: Situation updated as of 11th May 2015. [Online]. Available: http://drrportal.gov.np/uploads/document/14.pdf

[4] A. R. Ghumman, Y. M. Ghazaw, A. R. Sohail, and K. Watanabe, "Runoff forecasting by artificial neural network and conventional model," Alexandria Engineering Journal, vol. 50, pp. 345-350, 2011.

[5] Department of Hydrology and Meteorology. Meteorological forecasting division. Kathmandu, Nepal, [Online]. Available: http://www.mfd.gov.np/

[6] Kathmandu Central Bureau of Statistics, National Planning Commission Secretariat, Government of Nepal, "Annual Household Survey 2012-2013," CBS 2014.

[7] World Weather, [Online]. Available: https://www.worldweatheronline.com/

[8] I. Aichouri, A. Hani, N. Bougherira, L. Djabri, H. Chaffai, and S. Lallahem, "River flow model using artificial neural networks," Energy Procedia, vol. 74, pp. 1007-1014, August 2015.
[9] J. Veintimilla-Reyes, F. Cisneros, and P. Vanegas, "Artificial neural networks applied to flow prediction: a use case for the tomebamba river," in Proc. International Conference on Efficient \& Sustainable Water Systems Management toward Worth Living Development, 2nd EWaS 2016, vol. 162, pp. 153-161.

[10] C. Chiamsathit, A. J. Adeloye, and S. Bankaru-Swamy, "Inflow forecasting using artificial neural networks for reservoir operation," in Proc. the International Association of Hydrological Sciences, vol. 373 , pp. 209-214, 2016.

[11] M. Al Mamun, "Long-term Load Forecasting and Its Application to Power Deregulation," Ph.D. dissertation, Department of Electronics and Information Engineering, Tokyo University of Agriculture and Technology, Tokyo, Japan, 2008.

[12] S. H. Elsafi, "Artificial neural networks (ANNs) for flood forecasting at dongola station in the river nile, sudan," Alexandria Engineering Journal, vol. 53, pp. 655-662, September 2014

[13] I. Aichouri, A. Hani, N. Bougherira, L. Djabri, H. Chaffai, and S. Lallahem "River flow model using artificial neural networks," in Proc. International Conference on Technologies and Materials for Renewable Energy, Environment and Sustainability, TMREES 15, Energy Procedia, vol. 74, pp. 1007-1014, 2015.

[14] B. A. Nasir, "Design Considerations of Micro-hydro-electric Power Plant," Technologies and Materials for Renewable Energy, Environment and Sustainability (TMREES14- EUMISD), vol. 50, pp. 19-29, 2014.

[15] R. Rai and K. Nagasaka, "Modeling and development of run-of-river cascade hydropower plants in Nepal," Journal of Clean Energy Technologies, vol. 5, no. 6, pp. 469-474, November 2017.

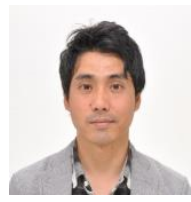

Raju Rai received his master's degree in electrical and electronics engineering from Tokyo University of Agriculture and Technology, Japan in 2015. Currently he is working toward the Ph.D program in the field of development of renewable energy in the Department of Electronic and Information Engineering at the Tokyo University of Agriculture and Technology, Tokyo, Japan His research mainly focuses on optimization, modeling and simulation of cascade hydropower plants for run-of-river

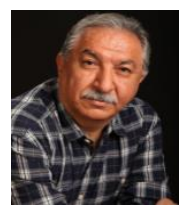

Ken Nagasaka obtained his Ph.D in electrical engineering from Tokyo Metropolitan University (1990). He became a chief researcher at CSD Company, Tokyo (1990-1991). He became a visiting professor at University of Manitoba Winnipeg, Canada (1991-1994). He worked as a scientist at Central Research Institute of Electric Power Industry, Tokyo (1994-1998). He became an associate professor a the Department of Electrical Engineering of Tokyo Metropolitan University (1995-1998). Since 1998 he taught and researched at the Graduate School of Engineering, Tokyo University of Agriculture and Technology. Currently he is a professor of Tokyo University of Agriculture and Technology. Prof Nagasaka has published more than 600 papers in the area of power systems and renewable energies. 